\title{
Infeksi Anisakid pada lumba-lumba hidung botol indo-pasifik (Tursiops aduncus) di situs konservasi lumba-lumba, Indonesia
}

\author{
Ismah Atika Salmah $^{1, *}$, Risa Tiuria ${ }^{2}$, Agus Setiyono ${ }^{3}$, Tri Isyani Tungga Dewi ${ }^{4}$ \\ ${ }^{1}$ Program Sarjana Fakultas Kedokteran Hewan, Institut Pertanian Bogor, Bogor \\ ${ }^{2}$ Divisi Parasitologi dan Entomologi Kesehatan, Departemen Ilmu Penyakit Hewan dan Kesmavet, Fakultas Kedokteran \\ Hewan, Institut Pertanian Bogor, Bogor \\ ${ }^{3}$ Divisi Patologi, Fakultas Kedokteran Hewan, Institut Pertanian Bogor, Bogor \\ ${ }^{4}$ Rumah Sakit Hewan Pendidikan, Institut Pertanian Bogor, Bogor
}

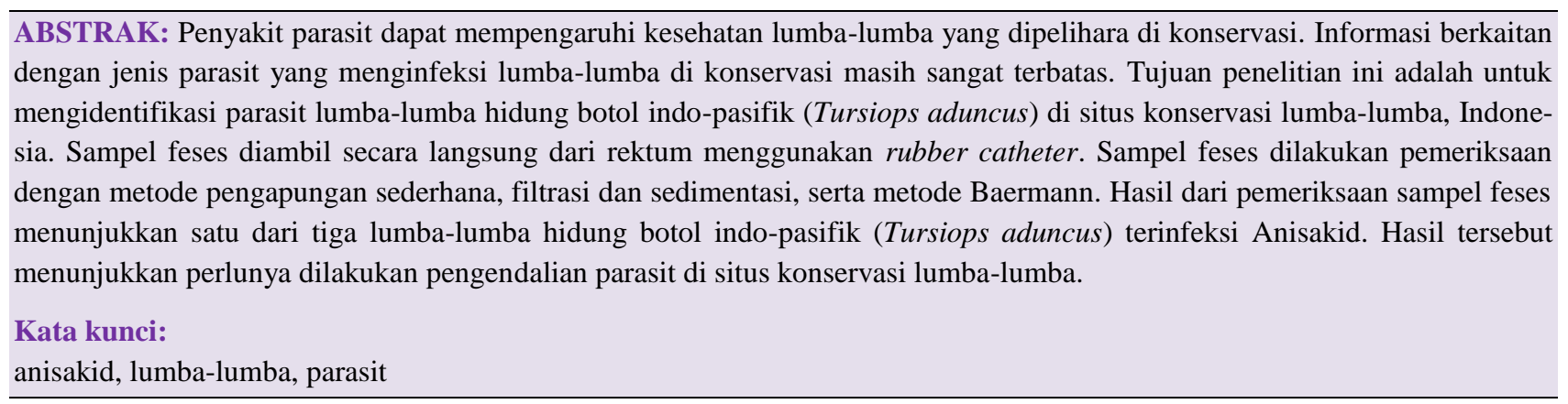

\section{- PENDAHULUAN}

Lumba-lumba adalah hewan mamalia laut kerabat paus dan pesut. Terdapat lebih dari 40 jenis lumba-lumba yang telah dikenal di dunia yang hidup di laut dan sungai (Jefferson et al,1993). Secara umum, lumba-lumba telah banyak dilaporkan sebagai inang definitif untuk parasit protozoa, nematoda, trematoda, dan acanthocephala (Quiñones et al, 2013). Beberapa parasit yang telah dilaporkan pada lumba-lumba merupakan parasit zoonosis seperti Giardia spp., Cryptosporidium spp., Anisakis spp., dan Diphyllobothrium spp. (Kleinertz et al, 2014). Penelitian terkait infeksi parasit lumba-lumba telah dilakukan pada lumba-lumba hidup bebas di habitat alamiahnya, terdampar, atau tertangkap. Pemeriksaan parasitik umumnya dilakukan post mortem melalui nekropsi dan imunodiagnostik (Jaber et al, 2006), sedangkan penelitian yang dilakukan pada lumba-lumba di konservasi masih jarang dilakukan. Penelitian ini bertujuan untuk mengidentifikasi parasit lumba-lumba hidung botol indopasifik (Tursiops aduncus) di situs konservasi lumba-lumba.

\section{- BAHAN DAN METODE}

Sampel feses diambil dari tiga ekor lumba-lumba hidung botol (Tursiops aduncus) dari $10 \%$ populasi di situs konservasi lumba-lumba.

Pengambilan sampel feses. Lumba-lumba diberi kode oleh pelatih untuk menuju ke pinggir kolam. Bagian rektum dibersihkan menggunakan antiseptic gauze pad. Rubber catheter dimasukkan ke dalam rektum sedalam 5-10 cm, syringe yang telah berisi $\mathrm{NaCl} 0,9 \%$ sebanyak $20 \mathrm{ml}$ dihubungkan dengan ujung rubber catheter, piston ditekan untuk memasukkan $\mathrm{NaCl}$ ke dalam rektum. Syringe diaspirasi dengan cara menarik piston. Sampel feses yang diperoleh dimasukkan ke dalam pot plastik (Gambar 1).

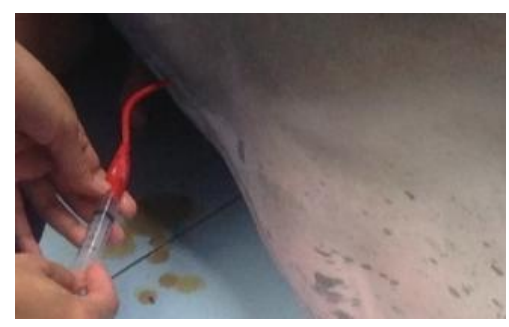

Gambar 1 Pengambilan sampel feses

Feses yang telah diperoleh kemudian diperiksa dengan beberapa metode sebagai berikut:

a. Pengapungan sederhana. Sampel feses sebanyak $1 \mathrm{ml}$ dimasukkan ke dalam tabung reaksi. Larutan pengapung ditambahkan sampai membentuk miniskus, kemudian ditutup menggunakan gelas penutup dan dibiarkan selama 5 menit. Gelas penutup diangkat dan diletakkan di atas gelas objek. Pemeriksaan feses dilakukan dibawah mikroskop dengan perbesaran 200 dan 400 kali.

Diterima: 16-09-2018 | Direvisi: 30-10-2018 | Disetujui: 06-11-2018 (C) 2018 CC-BY-SA. Ini adalah artikel Open Access yang didistribusikan berdasarkan ketentuan dari Creative Commons Attribution ShareAlike 4.0 International License (https://creativecommons.org/licenses/by-sa/4.0/). 
b. Filtrasi dan sedimentasi. Sampel feses sebanyak $4 \mathrm{ml}$ ditambahkan $56 \mathrm{ml}$ aquades pada gelas plastik, kemudian disaring menggunakan saringan teh. Hasil saringan difiltrasi menggunakan saringan bertingkat dengan ukuran celah permiabel 400, 100, dan $45 \mu \mathrm{m}$. Filtrat yang ada pada saringan $45 \mu \mathrm{m}$ ditampung pada gelas Baermann kemudian ditambahkan aquades, dan diamkan selama 30 menit. Setelah itu supernatan dibuang, sedimen dikumpulkan pada cawan petri, dan diamati dibawah stereo mikroskop dengan perbesaran 100 dan 200 kali.

c. Metode Baermann. Sampel feses dibungkus menggunakan kertas saring, kemudian diletakkan menggantung dengan posisi terendam dalam gelas Baermann yang telah diisi aquades. Feses dibiarkan 4 jam agar larva turun ke dasar gelas. Larva yang terkumpul di dasar gelas dimasukkan ke dalam tabung Eppendorf dan disimpan di dalam refrigerator, hingga saat identifikasi.

\section{- HASIL DAN PEMBAHASAN}

Hasil pemeriksaan feses dengan metode pengapungan sederhana ditemukan satu ekor cacing nematoda dari satu lumba-lumba. Cacing nematoda yang ditemukan memiliki morfologi dengan bentuk gilig (Gambar 2). Bagian anterior memiliki nerve ring terletak dekat dengan ujung anterior tubuh, esofagus dilengkapi dengan ventrikel yang relatif besar, ventrikel langsung berhubungan dengan usus, dan tidak dilengkapi sekum (Gambar 2 A). Bagian posterior terlihat adanya mukron (Gambar 2 B). Berdasarkan ciri-ciri morfologi tersebut termasuk dalam kelompok Anisakid. Menurut Anderson et al. (2009), Anisakid memiliki karakteristik esofagus dilengkapi dengan ventrikulus yang membujur sampai silindris, dengan beberapa spesies memiliki sekum. Ciri morfologi lainnya berupa mukron pada beberapa spesies di bagian posterior.

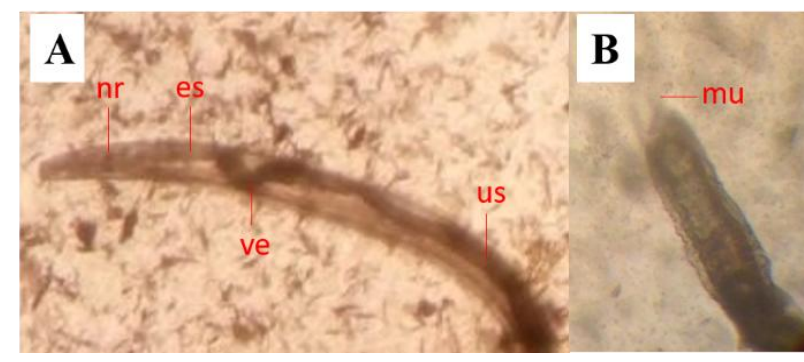

Gambar 2 Anisakid: $\mathrm{A}$ anterior, $\mathrm{B}$ posterior $(\mathrm{nr}=$ nerve ring, es $=$ esophagus, ve $=$ ventrikulus, us $=$ usus, $\mathrm{mu}=$ mukron $)$.

Lumba-lumba terinfeksi Anisakid saat memakan ikan yang terinfeksi larva stadium 3 (L3) Anisakid (Parker dan Parker, 2002). Lumba-lumba hidung botol di alam umumnya memakan berbagai spesies ikan, crustacea, dan cephalopoda. Beberapa ikan yang tersebar di perairan Indonesia dilaporkan terinfeksi larva Anisakid yaitu, ikan tongkol lisong, tongkol balaki, cakalang, kuwe, kembung lelaki, dan kerapu (Anshary et al, 2014). Peneliti lainnya, Utami (2016) melaporkan larva Anisakis sp. ditemukan pada ikan selar, swagi, kembung, dan tenggiri, dengan ting- kat prevalensi tertinggi pada ikan selar 23,33\%, ikan lainnya antara 3,23\%-16,67\%. Lumba-lumba di konservasi dapat terinfeksi Anisakid dari pakan yang diberikan, seperti ikan selar yang diperoleh dari laut Jawa dan reinfeksi Anisakid dapat terjadi.

Pengendalian Anisakid di konservasi dilakukan dengan pemberian anthelmintika secara berkala. Pengendalian akan lebih efektif apabila dikombinasikan dengan membekukan ikan dengan suhu rendah untuk membunuh larva Anisakid. Pembekuan pada temperatur $-20{ }^{\circ} \mathrm{C}$ selama 168 jam efektif membunuh larva Anisakis (Baladin 2007).

\section{- SIMPULAN}

Satu dari tiga lumba-lumba yang diperiksa di situs konservasi lumba-lumba di Indonesia terinfeksi Anisakid.

\section{- INFORMASI PENULIS}

Penulis untuk Korespondensi

*IAS: ismahatika16@yahoo.com

Fakultas Kedokteran Hewan, Institut Pertanian Bogor, Bogor

J1. Agatis Kampus IPB Dramaga Bogor 16680

\section{— UCAPAN TERIMA KASIH}

Situs konservasi lumba-lumba atas izin pengambilan sampel. Staf teknisi Lab helminthologi Fakultas Kedokteran Hewan, Institut Pertanian Bogor atas bantuan dalam pemeriksaan sampel.

\section{- PUSTAKA ACUAN}

Anderson RC, Chabaud AG, Willmott S. 2009. Key to the Nematode Parasite of Vertebrates. Wallingford Oxon (GB): CAB International.

Anshary H, Sriwulan, Freeman MA, Ogawa K. 2014 Occurrence and molecular identification of Anisakis Dujardin, 1845 from marine fish in southern Makassar Strait, Indonesia. Korean J Parasitol. 52(1): 9-19.

Baladin OL. Studi ketahanan hidup larva Anisakidae dengan suhu pembekuan dan penggaraman pada ikan kembung (Rastrelliger spp.) [Skripsi]. Bogor (ID): Institut Pertanian Bogor.

Jaber JR, Pérez J, Arbelo M, Zafra R, Fernández A . 2006. Pathological and immunohistochemical study of gastrointestinal lesions in dolphins stranded in the Canary Islands. Vet Rec. 159:410-414.

Jefferson TA, Leatherwood S, Webber MA. 1993. Marine Mammals of the World. Rome (RO): United Nations Environment Programme Food and Agriculture Organization of The United Nations.

Kleinertz S, Hermosilla C, Ziltener A, Kreicker S, Hirzmann J, Abdel-Ghaffar F, Taubert A. 2014. Gastrointestinal parasites of free-living Indo-Pacific bottlenose dolphins (Tursiops aduncus) in the Northern Red Sea, Egypt. Parasitol Res. 113(4):1405-15. Parker JN, Parker PM, 2002. The Official Patient's Sourcebook of Anisakiasis. San Diego (US): ICON Health Publication.

Quiñones R, Giovannini A, Raga JA, Fernández M. 2013. Intestinal helminth fauna of bottlenose dolphin (Tursiops truncatus) and common dolphin (Delphinus delphis) from the Western Mediterranean. J Parasitol. 99(3):576-579.

Utami P. 2014. Identifikasi Anisakis sp. pada beberapa ikan laut di beberapa tempat pelelangan ikan (TPI) Cilacap. JMST. 15(1):2128. 